\title{
Electrodeposition of Pt and Gd from the Same Ionic Liquid
}

\author{
L. Asen, ${ }^{\mathrm{a}, \mathrm{b}}$ S. Martens, ${ }^{\mathrm{a}}$ U. Heiz, ${ }^{\mathrm{b}}$ A. Knoll, ${ }^{\mathrm{a}}$ and O. Schneider ${ }^{\mathrm{a}}$ \\ a Institute of Informatics VI, Technical University of Munich, 85748 Garching, Germany \\ ${ }^{b}$ Department of Chemistry, Technical University of Munich, 85748 Garching, Germany
}

\begin{abstract}
Platinum rare earth alloys show several times higher electrocatalytic activity for the oxygen reduction reaction than pure platinum while still maintaining an excellent stability. However, the high reactivity of rare earth elements makes the preparation of such alloys with scalable methods challenging. The electrodeposition from ionic liquids seems to be a possible route. In this work, we demonstrate the electrodeposition of the rare earth metal gadolinium from the ionic liquid butylmethylimidazolium dicyanamide at elevated temperatures. The deposition of Pt metal from this ionic liquid has been studied using several different precursors.
\end{abstract}

\section{Introduction}

When low temperature proton exchange membrane fuel cells are manufactured in large scale, then the large platinum content becomes a major cost factor (1). The major reason for the higher Pt loading at the cathode is the sluggish kinetics of the oxygen reduction reaction (ORR) and the resulting large overpotential (1-5). The fuel cell vehicle from Toyota has a loading of $0.26 \mathrm{~g} \mathrm{Pt} \mathrm{kW}^{-1}$ maximum power based on published Pt content and the output power of the vehicle. The DOE target for 2020 is $0.125 \mathrm{~g} \mathrm{Pt} \mathrm{kW}^{-1}$ (6). Therefore, there is a strong need for more active catalysts permitting the use of less Pt. One major strategy is the use of alloy catalysts. Alloying can alter the interaction with the ORR intermediates and in turn enhance the overall reaction rate $(7,8)$. In many cases, such alloys form a thin overlayer of pure Pt (skin or skeleton) at the surface due to surface segregation and/or electrochemical de-alloying processes (9-13). Examples for such alloys are the well-known and highly active $\mathrm{Pt}_{3} \mathrm{Ni}$ and other Pt-transition metal alloys (10-12, 14-16), including the recently discussed Pt-Ni nanoframes (17-19), but especially alloys between $\mathrm{Pt}$ and rare earth (RE) metals (7, 13, 20-23). Pt-rare earth catalysts show a 3-6 times higher activity compared to Pt as initial de-alloying leads to a 4-6 atomic layers thick compressed Pt skin on the alloy core $(13,23)$, i.e. due to the strain effect $(24,25)$. In addition, the catalysts show excellent stability, especially Pt-Gd (13, 22). For $8 \mathrm{~nm}$ large nanoparticles of the latter prepared in a UHV cluster source, an activity of $3.6 \mathrm{~A} \mathrm{mg}^{-1} \mathrm{Pt}$ has been reported (22).

However, a scalable method is required for actual transfer of this type of catalyst into membrane electrode assemblies (MEA) for entire fuel cell stacks. Due to the very negative standard potentials of the rare earth metals and their high affinity towards oxygen and water, this is no easy task. Sputtering is a viable method when aiming at nanostructured thin film catalysts. Successful sputtering of these catalysts has been demonstrated in literature (26-28). However, chemical or electrochemical methods are 
required for the preparation of carbon supported nanoparticles. Due to the wide electrochemical potential window of ionic liquids (IL), the simultaneous reduction of $\mathrm{Pt}$ and rare earth metal should be doable. A number of reports have addressed the electrochemical deposition of rare earth metals from ionic liquids (29-35). The electrodeposition of RE metal from $\mathrm{RE}^{3+}$ ions is often not a single step process but involves the intermediate formation of a lower valency species (36-38) which is stable for some RE/IL combinations, and disproportionates to metal and $\mathrm{RE}^{3+}$ for others (36-39). Especially in butylmethylpyrrolidinium bistrifluoromethylsulfonylimide (BMP TFSI), surface passivation instead of metal deposition was observed for a number of RE metals, like $\mathrm{Ce}$, Pr and $\mathrm{Nd}(36,37)$. Many studies on RE metal deposition were characterized by the absence of a corresponding dissolution peak $(30,33,34,40)$, which is explained by slow charge transfer kinetics or reactions with residual moisture (33) or the ionic liquid (34). Eu was successfully deposited from tetramethylphosphonium (TMP) TFSI and trimethylbutylammonium TFSI $(33,41)$ and evidenced by the formation of a metallic grey layer rapidly oxidizing at air. The deposition of Sm was accomplished in BMP TFSI at $120^{\circ} \mathrm{C}(40) . \mathrm{Nd}$ and Dy were deposited from different ILs (29, 30, 42, 43). The deposition of La was reported from octylmethylpyrrolidinium (OMP) TFSI (34) and, by Zhang et al., from butylmethylimidazolium dicyanamide (BMIm DCA) at $60^{\circ} \mathrm{C}(35)$. In the latter work, also a dissolution peak was obtained, and the nature of the deposit formed potentiostatically was supported by SEM, XRD and XPS measurements. As our own earlier electrodeposition experiments of $\mathrm{Y}$ and La from OMP TFSI and N,N-diethyl-Nmethyl-N-(2-methoxyethyl)ammonium tetrafluoroborate $\left(\left(\mathrm{N}_{122,2 \mathrm{O} 1}\right) \mathrm{BF}_{4}\right)$ had not been successful (44), we adapted the La deposition procedure by Zhang et al. for Gd deposition, selecting thus BMIm DCA as IL.

The electrodeposition of $\mathrm{Pt}$ has been reported in literature from $\mathrm{BMIm}_{\mathrm{BF}}$ (45), BMIm $\mathrm{PF}_{6}(45)$, and $\left(\mathrm{N}_{122,2 \mathrm{O}}\right) \mathrm{BF}_{4}(46)$ using hexachloroplatinate $\left(\mathrm{K}_{2} \mathrm{PtCl}_{6}\right.$ or $\left.\mathrm{H}_{2} \mathrm{PtCl}_{6}\right)$ as precursor, from BMP DCA using $\mathrm{PtCl}_{2}(47,48)$ and from BMP TFSI $+\mathrm{BMP} \mathrm{Cl}+\mathrm{PtCl}_{2}$ (48). We successfully deposited $\mathrm{Pt}$ nanoparticles from $\mathrm{H}_{2} \mathrm{PtCl}_{6}$ in $\left(\mathrm{N}_{122,2 \mathrm{O}}\right) \mathrm{BF}_{4}$ or OMP TFSI (44). In both cases, the typical two reduction (and oxidation) waves for the $\mathrm{Pt}(\mathrm{IV}) / \mathrm{Pt}(\mathrm{II})$ and the $\mathrm{Pt}(\mathrm{II}) / \mathrm{Pt}(0)$ peak couple were observed, as reported already in (46). As even traces of water might be harmful to the deposition of alloys with RE elements, we selected different water-free precursors for the current study in addition to chloroplatinic acid hydrate. Both $\mathrm{Gd}$ and $\mathrm{Pt}$ deposition were studied with the electrochemical quartz crystal microbalance technique (EQCM).

\section{Experimental}

All glassware and Teflon parts used for the experiments were cleaned sequentially in an alkaline and an acidic cleaning bath, and boiled several times in ultrapure water before and after each cleaning step. Pt wires were cleaned by annealing in a Bunsenburner flame. The EQCM resonators (KVG GmbH, $10 \mathrm{MHz}$ AT cut, $14 \mathrm{~mm}$ diameter, keyhole-shaped optically polished $\mathrm{Au}$ electrodes on $\mathrm{Cr}$ adhesion layer on each side) were inserted into custom-made cells, which were then transferred into an Argon filled glovebox (MBraun UNIlab plus eco) in which all experiments including electrolyte preparation were carried out. Different cells were used: small volume cells made from Teflon embedded in a steel housing that permitted measurements with $0.6 \mathrm{ml}$ of electrolyte at room temperature, and two types of custom-made double-jacketed glass cells with a quartz crystal (or general 
working electrode) holder made from Teflon. The latter cells require larger electrolyte volumes but can be temperature controlled. This was achieved by connecting a Julabo $600 \mathrm{~F}$ thermostat outside the glovebox filled with Julabo Thermal H10 silicon oil via tubing and a stainless steel feedthrough to the cooling mantle of the glass cells. In all measurements, the quartz crystals were attached at the bottom of the cell. One of the Au electrodes of the quartz served as the working electrode (WE; electrochemically active geometric area of $0.27 \mathrm{~cm}^{2}$ and piezoelectric active area of $0.19 \mathrm{~cm}^{2}$, facing upwards). $\mathrm{Pt}$ wires serves as counter (CE) and quasi reference (RE) electrodes. The electrical admittance spectra between the gold electrodes of the quartz crystal resonators were measured in the vicinity of the resonance frequency in parallel to the electrochemical measurements with an Agilent E5100A network analyzer; the real part of the admittance was fitted to a Lorentz function to determine the resonance frequency $f$ and the damping $w$ of the quartz. The changes in both parameters in the course of an experiment were determined by subtracting the numbers at the beginning of the experiment, leading to $\Delta f$ and $\Delta w$. The change in mass $\Delta m$ on the working electrode can be calculated from $\Delta f$ provided that $\Delta f<<\Delta w$ (49) using Sauerbrey's equation (50). Electrochemical measurements were carried out using a Solartron SI1287A electrochemical interface. For pulsed electrodeposition measurements, an Agilent 33220A function generator was connected to the potentiostat. All measurements were computer controlled using in-house software. The instruments were connected via a GPIB interface card or USB to the computer. The conductivity of selected IL and electrolyte samples was measured over a wide temperature range using a Mettler-Toledo Inlab 751 conductivity probe connected to a Solartron SI1260 Frequency Response Analyzer. The samples were placed in a small test tube inserted into fitting bore holes in a custom made, temperature controlled steel block. A full impedance spectrum was recorded with an applied AC voltage of $0.02 \mathrm{~V}$ and in a frequency range between $1 \mathrm{~Hz}$ and $10 \mathrm{MHz}$. The ohmic resistance of the electrolyte was determined based on the real part of the impedance where the imaginary part of the impedance is (close to) 0 . The specific conductivity was determined using a cell constant of $1 \mathrm{~cm}^{-1}$ calibrated with $0.1 \mathrm{M} \mathrm{KCl}$.

BMIm DCA (Iolitec, IL-0010-HP) was dried by heating it to $60^{\circ} \mathrm{C}$ under vacuum. The IL was continuously stirred during the drying procedure. The different electrolytes were prepared by weighing appropriate amounts of precursor salts and dissolving them into the electrolytes, as described below. The electrolytes were again heat-treated under vacuum to remove impurities.

The electrolyte containing Pt precursors were typically prepared by either dissolving $0.197 \mathrm{~g} \mathrm{Pt}(\mathrm{acac})_{2}$ (Sigma Aldrich, 99,98\%) in $21.324 \mathrm{~g} \mathrm{BMIm}$ DCA, $0.266 \mathrm{~g}$ of $\mathrm{PtCl}_{2}$ (Sigma Aldrich, 99,99\%) in $21.324 \mathrm{~g}$ BMIm DCA, or $0.337 \mathrm{~g} \mathrm{PtCl}_{4}$ (Alfa Aesar, 99.99\%) in $21.324 \mathrm{~g}$ BMIm DCA, each resulting in a $25 \mathrm{mM}$ solution. In addition, a $\sim 30 \mathrm{mM} \mathrm{Pt}$ precursor solution was prepared by adding $\sim 40 \mathrm{ml}$ of BMIm DCA stepwise to a mixture of $0.4545 \mathrm{~g} \mathrm{BMIm} \mathrm{Cl}$ (Iolitec, IL-0014-HP, 99\%) and $0.4341 \mathrm{~g} \mathrm{PtCl}_{4}$, and a $10 \mathrm{mM}$ solution by adding $0.052 \mathrm{~g} \mathrm{H}_{2} \mathrm{PtCl}_{6}$ (Sigma Aldrich, $37.50 \% \mathrm{Pt}$ ) to $10.662 \mathrm{~g} \mathrm{BMIm} \mathrm{DCA.}$ The Gd electrolytes were prepared by dissolving $1.150 \mathrm{~g} \mathrm{GdCl}_{3}$ (Sigma Aldrich, 99.99\%) in $58.541 \mathrm{~g} \mathrm{BMIm}$ DCA (0.08 M solution). In addition, it was attempted to prepare a 0.25 $\mathrm{M} \mathrm{GdCl}_{3}$ solution, but the solubility limit was exceeded. Mixed Pt-Gd electrolytes were prepared by dissolving the corresponding amounts of the selected Pt precursors and $\mathrm{GdCl}_{3}$ in the IL. All mixtures were heated under vacuum to $60^{\circ} \mathrm{C}$. 


\section{Results}

\section{Gadolinium Electrodeposition}

Initial experiments with BMIm DCA were conducted at room temperature to evaluate the electrochemical window of this IL. However, at room temperature one cannot reliably work with this IL, as after already one cycle the compliance voltage of the potentiostat is exceeded, and the applicable voltage range is dramatically reduced (cf. Figure 1). The formation of a brownish deposit on the counter electrode was observed.

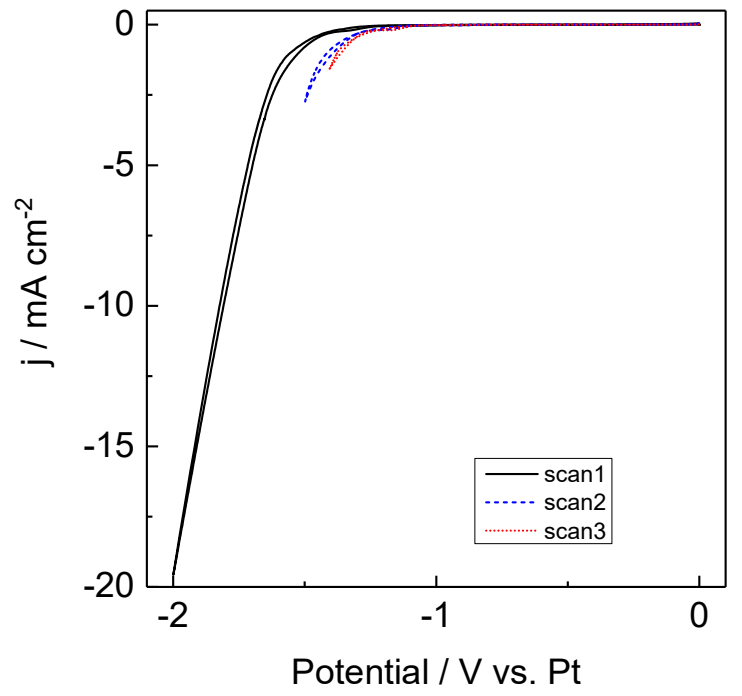

a)

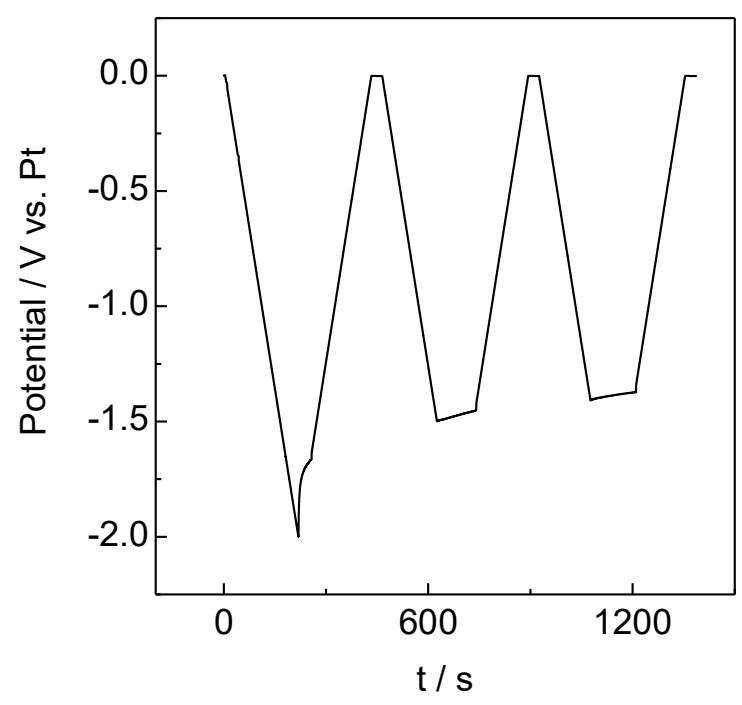

b)

Figure 1. Background voltammograms of $\mathrm{Au}$ at $25^{\circ} \mathrm{C}$ in BMIm DCA. Targeted conditions: $0 \mathrm{~V}-(-2 \mathrm{~V})$ at $10 \mathrm{mV} \mathrm{s}^{-1}$. a) measured voltammograms b) truly applied electrode potential as function of time.

The situation was improved at elevated temperatures, even though occasionally passivation still occurred. In a saturated $\mathrm{GdCl}_{3}$ electrolyte, voltammetric experiments at $57^{\circ} \mathrm{C}$ showed a clear cathodic peak close to $-1.75 \mathrm{~V}$ vs. a Pt quasi reference electrode pointing towards reduction of $\mathrm{Gd}(\mathrm{III})$ ions (cf. Figure 2). In parallel, a clear change in both the resonance frequency and the damping of the quartz was observed. As the damping change was very large, this alone was not an unequivocal proof for a deposition process. However, such a behavior can be indicative of the deposition of a rough layer. A dissolution peak was not observed in the potential range studied. During potential holds at more elevated potentials $(0.3 \mathrm{~V})$, though, an increase in the resonance frequency and a decrease in damping were observed.

A series of pulse deposition experiments was carried out to improve the deposition behavior. A typical example for a measurement curve is shown in Figure 3a. In that experiment, the pulse parameters were not yet optimized, and the current response steadily decreased. A more stable response was observed under the conditions shown in Figure $3 \mathrm{~b}$. In this experiment, the current density was rather stable for about $10 \mathrm{~min}$, then the compliance voltage was exceeded and the current rapidly declined. 


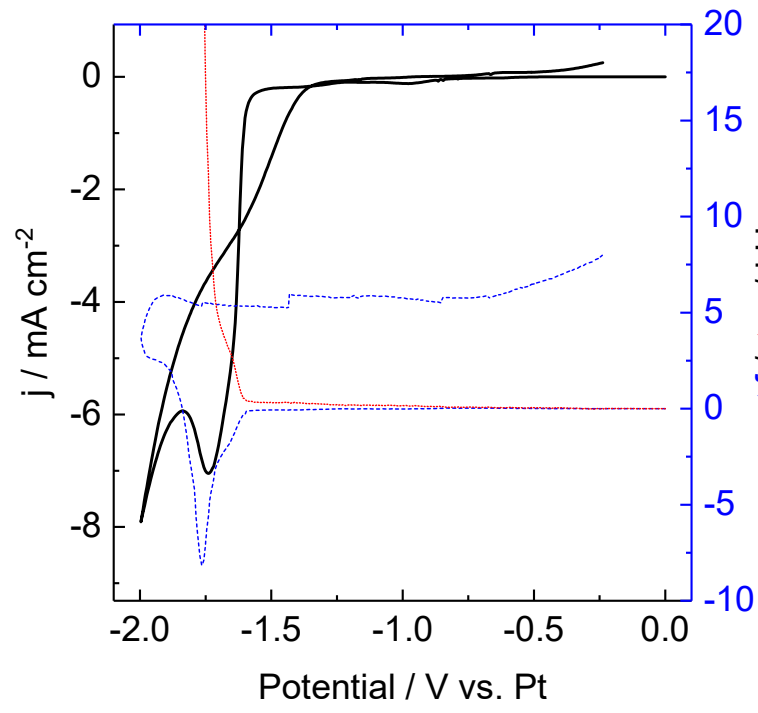

a)

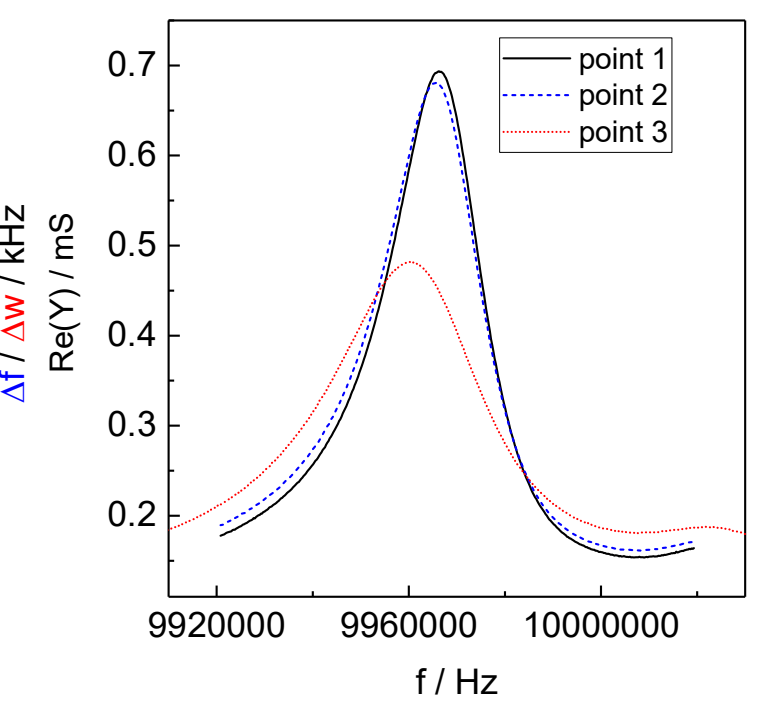

b)

Figure 2. a) EQCM Voltammogram at $\mathrm{Au}$ at $57^{\circ} \mathrm{C}$ in BMIm DCA saturated at room temperature with $\mathrm{GdCl}_{3}$. Current density (solid black line), change in quartz resonance frequency (dotted blue line) and damping (dashed red line). Scan rate: $5 \mathrm{mV} \mathrm{s}^{-1} . \mathrm{b}$ ) Admittance spectra of the quartz before the onset of reduction (point 1, $-1.45 \mathrm{~V}$ ), immediately thereafter (point 2, $-1.63 \mathrm{~V}$ ) and at the current peak (point 3,-1.75 V).

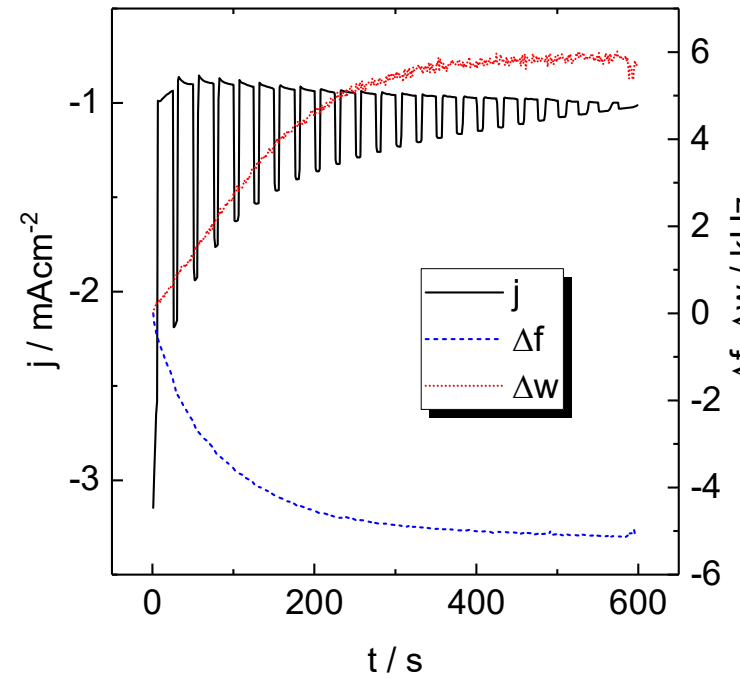

a)

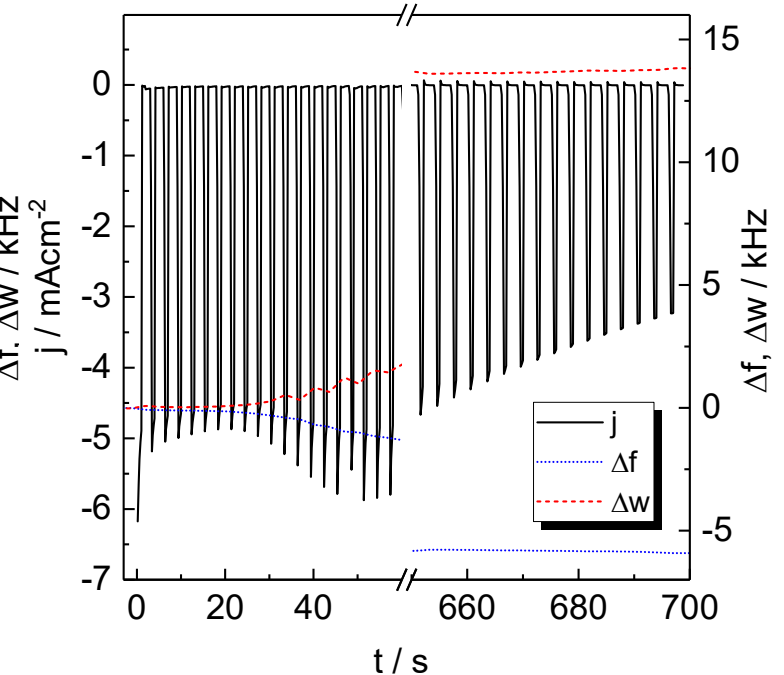

b)

Figure 3. Pulsed electrodeposition on $\mathrm{Au}$ at $60^{\circ} \mathrm{C}$ in $0.08 \mathrm{M} \mathrm{GdCl}_{3}$ in $\mathrm{BMIm} \mathrm{DCA}$ a) $\mathrm{t}_{\text {on }}$ $=5 \mathrm{~s}, \mathrm{E}_{\text {on }}=-1.75 \mathrm{~V}$ vs Pt, $\mathrm{t}_{\text {off }}=20 \mathrm{~s}, \mathrm{E}_{\text {off }}=-1.5 \mathrm{~V}$ vs Pt. b) $\mathrm{t}_{\text {on }}=1 \mathrm{~s}, \mathrm{E}_{\text {on }}=-1.6 \mathrm{~V}$ vs Pt, $\mathrm{t}_{\text {off }}$ $=2 \mathrm{~s}, \mathrm{E}_{\text {off }}=-0.8 \mathrm{~V}$ vs Pt. Current density (solid black line), change in quartz resonance frequency (dotted blue line) and damping (dashed red line).

The pulsed electrodeposition experiments resulted in the repeatable and reproducible deposition of thick grey metallic looking layers on the quartz (cf. Figure 4). When exposed to air and rinsed with isopropanol to remove remaining IL, a white discoloration was observed. This clearly indicates that indeed metallic Gd was deposited that oxidized in contact with air. 


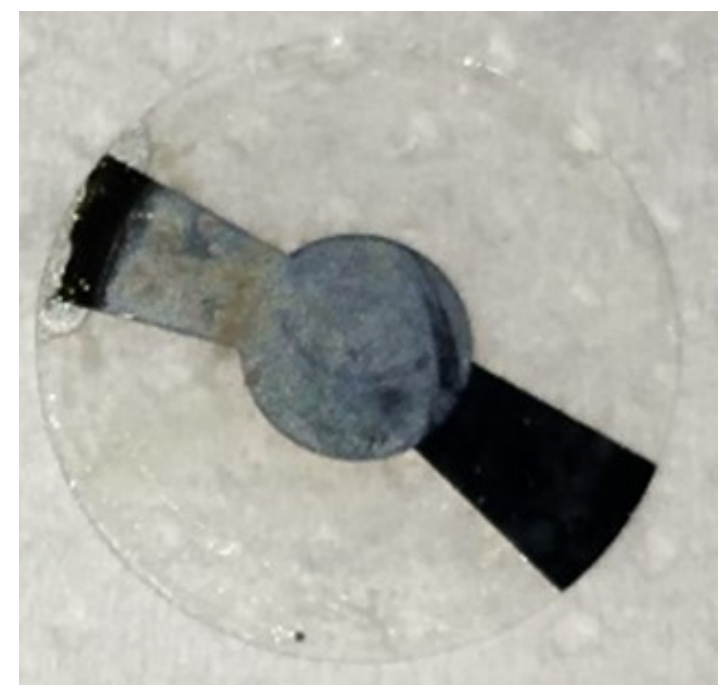

Figure 4. Photograph of grey layer deposited on the Au electrode of the quartz resonator during a pulsed electrodeposition experiment.

\section{$\underline{\text { Platinum Electrodeposition }}$}

A number of different precursors was tested to study the electrodeposition of $\mathrm{Pt}$ from BMIm DCA. These were Pt(acac) $)_{2}, \mathrm{PtCl}_{2}, \mathrm{PtCl}_{4}$, and $\mathrm{H}_{2} \mathrm{PtCl}_{6}+\mathrm{x} \mathrm{H}_{2} \mathrm{O}$. In some cases, also mixed electrolytes with $\mathrm{GdCl}_{3}$ were used to study the co-deposition of $\mathrm{Pt}$ and $\mathrm{Gd}$, which represents the ultimate target of the work carried out.

Platinum Acetylacetonate. Electrodeposition of Pt from $\mathrm{Pt}(\mathrm{acac})_{2}$ was not successful. The voltammograms showed a cathodic peak that was however not connected to significant changes in the resonance frequency of the quartz crystal resonators. When comparing the CVs of $25 \mathrm{mM} \mathrm{Pt(acac)_{2 }}$ in BMIm DCA to the ones of the pure IL, similarities are seen, even though the cathodic currents are slightly larger (cf. Figure 5a). As a Pt quasi-reference electrode was used, the potential scales are not identical, in fact it appears that the presence of $\mathrm{Pt}(\mathrm{acac})_{2}$ in the electrolyte led to negative shift in $\mathrm{RE}$ potential by $\sim 160 \mathrm{mV}$. Also potential step experiments were unsuccessful. Further polarization to even more negative potentials only led to a more rapid IL decomposition. Very interesting was the comparison between a voltammogram of pure $80 \mathrm{mM} \mathrm{GdCl} 3$ and $75 \mathrm{mM} \mathrm{GdCl}_{3}+25 \mathrm{mM} \mathrm{Pt}(\mathrm{acac})_{2}$ (Figure 5b): The presence of the Pt precursor strongly suppressed the $\mathrm{GdCl}_{3}$ reduction currents.

Platinum(II) Chloride. Voltammograms recorded in $0.05 \mathrm{M} \mathrm{PtCl}_{2}$ in $\mathrm{BMIm}^{\mathrm{DCA}}$ showed two pronounced cathodic shoulders before the onset of IL decomposition. EQCM data indicated the presence of a deposition process (Figure 6a). This was also seen during potentiostatic transients at a potential of $-2.2 \mathrm{~V}$. Nevertheless, the measured frequency change was almost two orders of magnitude less than expected from the measured charge and Sauerbrey equation, indicating a poor current efficiency.

Platinum(IV) Chloride. With this precursor, an additional cathodic process was visible at more positive potentials, between 0 and $-0.5 \mathrm{~V}$ (Figure $6 \mathrm{~b}$ ). At lower potentials, a cathodic shoulder was connected to a decrease in the resonance frequency but also to an 
increase in damping. The changes in the resonance frequency in this region were qualitatively similar to the results from $\mathrm{PtCl}_{2}$.

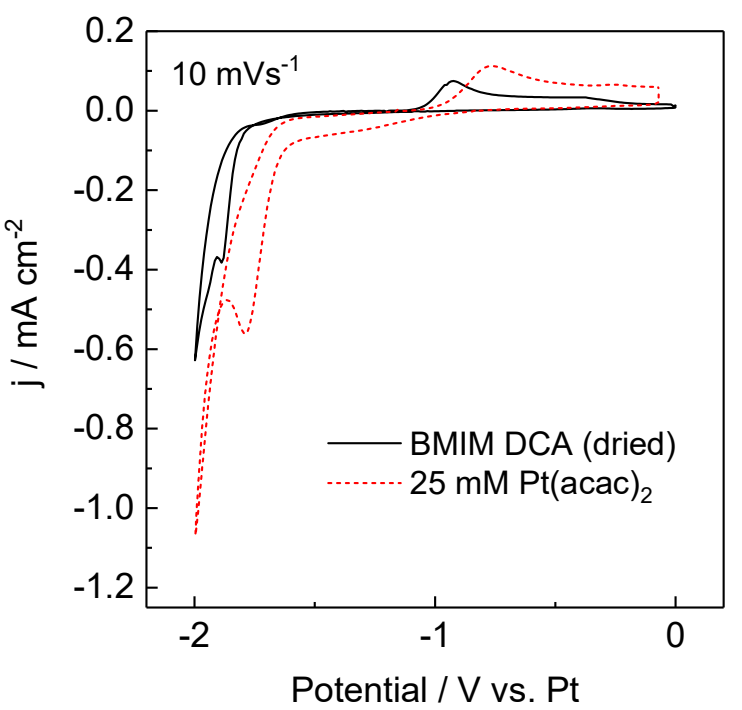

a)

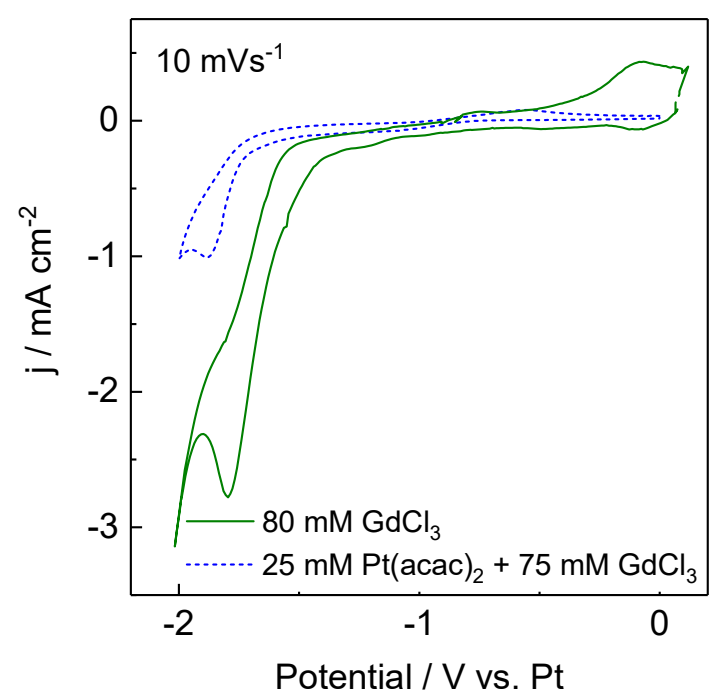

b)

Figure 5. Voltammograms at $\mathrm{Au}$ at $60^{\circ} \mathrm{C}$ in BMIm DCA at $10 \mathrm{mV} / \mathrm{s}$ a) background voltammogram in pure IL (solid black line) and in a $25 \mathrm{mM} \mathrm{Pt}(\mathrm{acac})_{2}$ solution (dashed red line). b) in $80 \mathrm{mM} \mathrm{GdCl}_{3}$ (solid green line) and in $75 \mathrm{mM} \mathrm{GdCl}_{3}+25 \mathrm{mM} \mathrm{Pt}(\mathrm{acac})_{2}$ solution (dashed blue line).

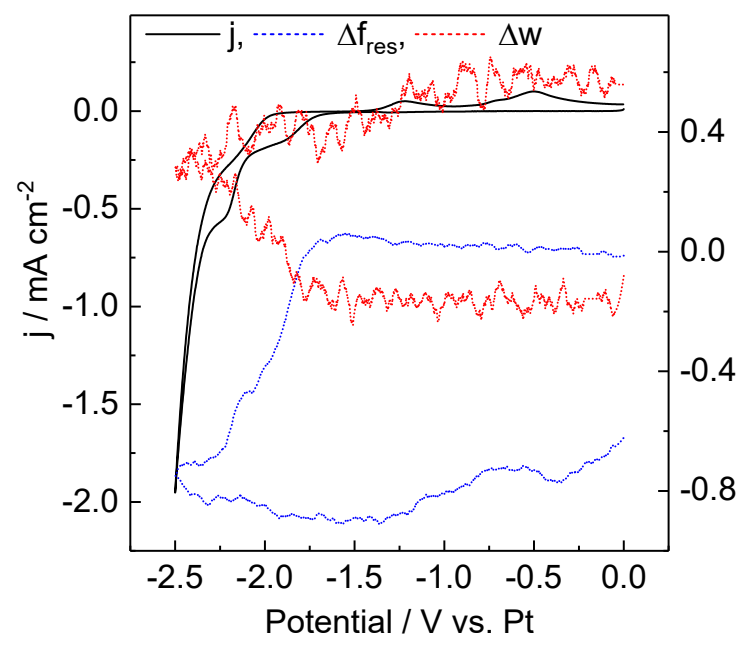

a)

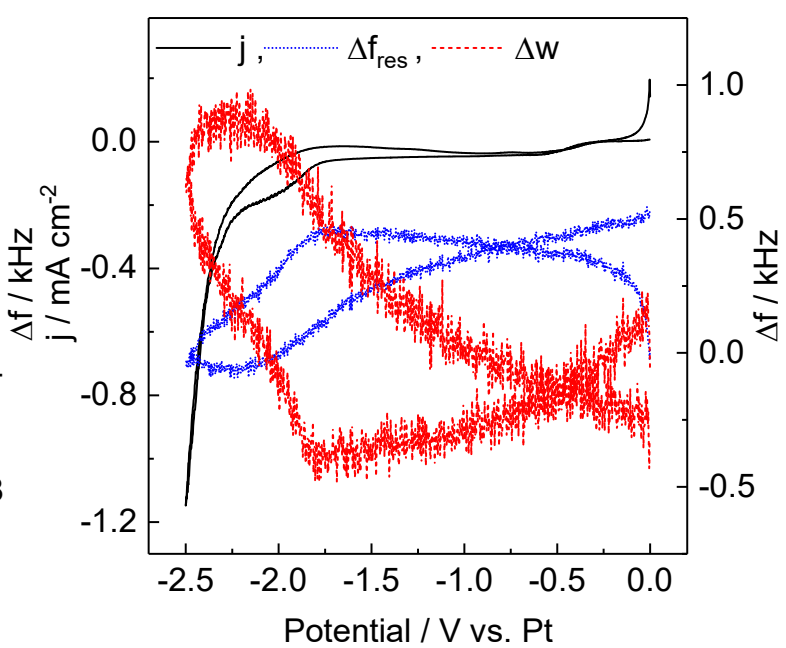

b)

Figure 6. Voltammograms at $\mathrm{Au}$ at $60^{\circ} \mathrm{C}$ a) in $50 \mathrm{mM} \mathrm{PtCl}_{2}$ in $\mathrm{BMIm}^{\mathrm{DCA}}$ solution at 2 $\mathrm{mV} \mathrm{s}^{-1}$. b) in $50 \mathrm{mM} \mathrm{PtCl}_{4}$ in BMIm DCA solution at $2 \mathrm{mV} \mathrm{s}^{-1}$. Current density (solid black line), change in quartz resonance frequency (dotted blue line) and damping (dashed red line)

BMIm Cl + Platinum(IV) Chloride. Typical voltammograms in this electrolyte bear similarities to the measurement in pure $\mathrm{PtCl}_{4}$ containing electrolyte. There was a very pronounced cathodic wave at $\sim-0.5 \mathrm{~V}$ that was connected to a stepwise change in $\Delta f$ and $\Delta w$ (cf. Figure 7a). Thereafter, both $\Delta f$ and $\Delta w$ remained rather constant until a new reduction process at $\sim-1.7 \mathrm{~V}$ set in. Now stronger changes in the EQCM parameters 
were observed, especially when lowering the lower reversal potential to $-2.5 \mathrm{~V}$ (cf. Figure $7 \mathrm{~b}$ ). The application of the Sauerbrey equation is not justified as the damping change is larger than the change in resonance frequency. Applying it nevertheless leads to an (apparent) mass change that is ten times less than expected from the charge. Lowering the potential even further leads to massive electrolyte decomposition associated with the appearance of a large anodic peak at $-0.63 \mathrm{~V}$.

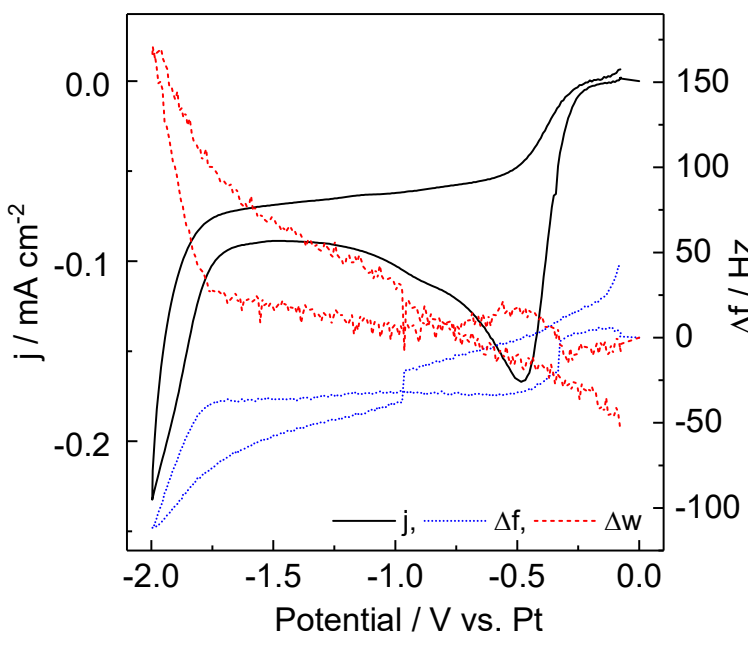

a)

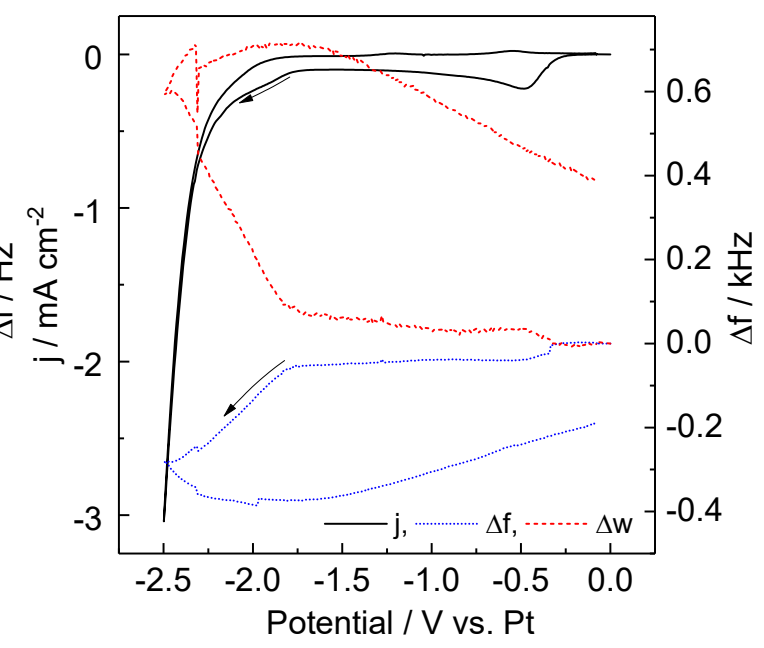

b)

Figure 7. Voltammograms at $\mathrm{Au}$ at $60^{\circ} \mathrm{C}$ in $30 \mathrm{mM} \mathrm{PtCl}_{2}+60 \mathrm{mM} \mathrm{BMIm} \mathrm{Cl}$ in BMIm DCA solution at $5 \mathrm{mV} \mathrm{s}^{-1}$. a) first cycle between 0 and $-2 \mathrm{~V} \mathrm{~b}$ ) first cycle between 0 and $-2.5 \mathrm{~V}$ vs. Pt quasi reference. Current density (solid black line), change in quartz resonance frequency (dotted blue line) and damping (dashed red line).

Hexachloroplatinic Acid Hydrate. Voltammograms recorded in $0.01 \mathrm{M} \mathrm{H}_{2} \mathrm{PtCl}_{6}$ electrolyte were qualitatively very similar to the one shown in Figure 7b. However, only a limited number of experiments could be carried out as the compliance voltage was exceeded rapidly.

\section{$\underline{\text { Physical Characterization of Selected Electrolytes }}$}

The conductivities of the pure IL and several electrolytes were measured as described in the experimental section. BMIm DCA shows much higher conductivities than, for instance, BMP TFSI. There was little difference between the as received BMIm DCA and the additionally dried IL. Addition of salt resulted in a lowering of the specific conductivity. The effect increased with the ionic strength of the salt. At $60^{\circ} \mathrm{C}$, the conductivity was increased by a factor of three compared to room temperature. 


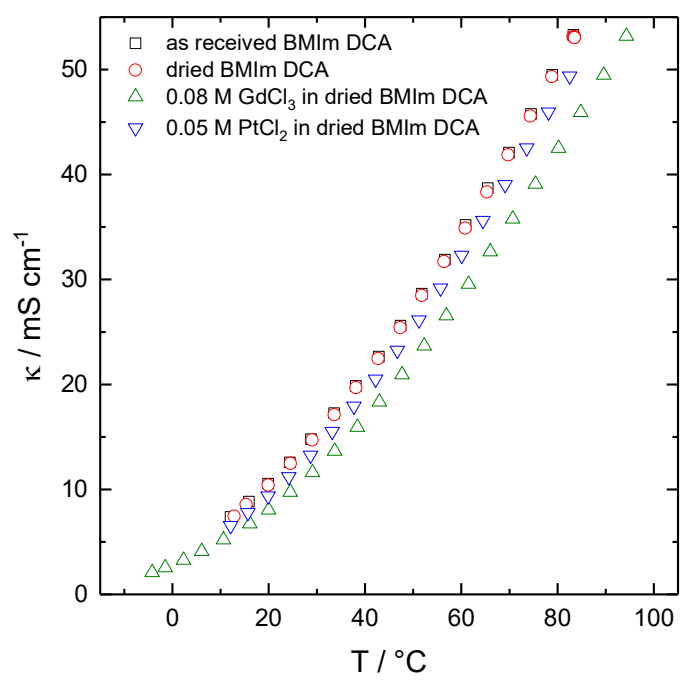

Figure 8. Specific conductivities of as received BMIm DCA, BMIm DCA after drying under vacuum at $60^{\circ} \mathrm{C}$, and electrolytes containing $\mathrm{GdCl}_{3}$ and $\mathrm{PtCl}_{2}$, determined by impedance spectroscopy.

\section{Discussion}

The electrodeposition of Pt-Gd alloys requires the simultaneous reduction of $\mathrm{Pt}$ and $\mathrm{Gd}$ precursors to the elements. In aqueous solutions, the standard potential for the reduction of $\mathrm{PtCl}_{6}{ }^{2-}$ to $\mathrm{PtCl}_{4}{ }^{2-}$ is $0.726 \mathrm{~V}$, and from $\mathrm{PtCl}_{4}{ }^{2-}$ to metallic $\mathrm{Pt} 0.758 \mathrm{~V}$ (51). The standard potential for the reduction of $\mathrm{Gd}^{3+}$ to metallic $\mathrm{Gd}$ is $-2.279 \mathrm{~V}$, the one for $\mathrm{La}^{3+}$ to La even $-2.379 \mathrm{~V}(51)$. Based on those numbers, the difference in standard potentials of $3 \mathrm{~V}$ would make the deposition of alloys very challenging. The only possibility would be to work with very low Pt concentrations and take advantage of mass transport limitations for the Pt precursor. Already earlier work has shown, though, that in ionic liquids the situation can be very different (44-46). Both in OMP TFSI and in $\left(\mathrm{N}_{122,2 \mathrm{O}}\right) \mathrm{BF}_{4}$, the potential for reduction of $\mathrm{Pt}(\mathrm{II})$ to $\mathrm{Pt}(0)$ is more negative than the one for reduction of $\mathrm{Pt}(\mathrm{IV})$ to $\mathrm{Pt}(\mathrm{II})$, different from aqueous electrolytes, and large overpotentials of $\sim 1.5 \mathrm{~V}$ were observed (44). While TFSI is not a strong complex former, this is different for dicyanamide, which can form strong complexes with Pt ions (47). Thus, one can expect in BMIm DCA even more negative Pt reduction potentials than in OMP TFSI. This should render the co-deposition of Pt and Gd feasible. Gd deposition was also expected as feasible, as it is chemically very similar to La (that had been successfully deposited in literature from BMIm DCA (35)) and the standard potential is even less negative (and no large difference in complexation is expected for the two metals).

At room temperature experiments in the IL were difficult (cf. Figure 1). While the cation has a limited stability towards cathodic potential, the IL is rather stable in the anodic regime, and in background measurements the (positive) currents were very small over a range of several volts. If an applied WE potential is connected with relatively large currents, then at the counter electrode relatively large potentials will be applied by the potentiostat. In addition the ohmic resistance contributes to the total voltage which is several times larger at room temperature compared to $60^{\circ} \mathrm{C}$. The formation of the 
brownish layer on the counter electrode after exceeding the compliance voltage indicates that at more extreme potentials of several Volts the anion polymerizes, and the counter electrode is passivated, causing an additional voltage drop at the counter electrode for a specific current. Thus the use of elevated temperature and a CE with a relatively large area are needed to carry out deposition experiments in this IL.

Indeed it was possible to deposit Gd from BMIm DCA at $60^{\circ} \mathrm{C}$ in large amounts easily visible with the eye (cf. Figure 4), as expected from the literature report on La deposition (35). The potential required to achieve deposition was still within the electrochemical stability window of the IL (cf. Figure 2). However, different from literature results for La, no dissolution peak was observed, at least not in a potential region that could be safely applied to the Au electrode on the EQCM quartz resonators. At more elevated potentials slow dissolution processes could be observed. This indicates that the deposit reacts to a certain extent with the ionic liquid or some residual moisture in the system, preventing its subsequent rapid dissolution. The causes for this behavior are under further study, as the standard potential of Gd is less negative than the one for La this behavior was not expected. A quantitative analysis of the EQCM data was not possible, as the deposit formed is very rough. This causes a huge damping change preventing the application of Sauerbrey's equation. The deposition of Pt metal and of PtGd alloys was much more difficult: The results obtained so far point to a rather sluggish Pt reduction from all the tested precursors (cf. Figure 5- Figure 7). Most promising were the results from $\mathrm{PtCl}_{2}$ (cf. Figure 6a). The potential required for deposition however is already close to the cathodic stability limit of the BMIm ion. This explains why only very low current efficiencies were calculated from the EQCM data, and it was not possible so far to detect Pt metal on the electrode. The lower stability of BMIm compared to BMP also clarifies, why in literature the deposition of Pt has been reported for BMP DCA (48), but did not succeed in our work to the required extent for alloy deposition. Another aspect can be that the ion concentration of the Pt precursors was less than those of the Gd precursors. For some ILs it has been shown that the precursor concentration influences the interfacial structure, and that too low concentrations can prevent deposition if the IL forms a multilayer structure at the interface $(52,53)$.

An approach often used in electrodeposition, also from ILs, is the controlled formation of complexes. A prominent example is the deposition of metallic aluminum from a mixture of EMIm $\mathrm{Cl}$ and $\mathrm{AlCl}_{3}$ in a ratio that leads to the formation of $\mathrm{Al}_{2} \mathrm{Cl}_{7}^{-}$as the IL anion (54). In part complex formation also aids in solubilization of metal precursors, an example being the addition of 2 equivalents of $\mathrm{BMP} \mathrm{Cl}$ to permit the dissolution of $\mathrm{PtCl}_{2}$ in BMP TFSI (48). In this work, it was attempted to create a (BMIm) ${ }_{2} \mathrm{PtCl}_{6}$ complex by mixing $\mathrm{BMIm} \mathrm{Cl}$ and $\mathrm{PtCl}_{4}$ before dissolving it in the IL. So far, however, this approach was not successful. On the one hand DCA is already a strong complex former, therefore competition between DCA and the chloride ions must be expected. This is supported by the fact that - other than for OMP TFSI and $\left(\mathrm{N}_{122,2 \mathrm{O}}\right) \mathrm{BF}_{4}$ - even hexachloroplatinic acid hydrate did not permit Pt deposition. In addition, any stronger complexation might further shift the reduction potential outside the electrochemical stability window of BMIm DCA.

Very interesting was the outcome from the co-deposition attempts. In BMIm DCA it was not only not possible to deposit Pt from $\mathrm{Pt}(\mathrm{acac})_{2}$, but also deposition of Gd from added $\mathrm{GdCl}_{3}$ was blocked through the presence of the Pt precursor (cf. Figure 5b). The 
conductivities of Pt and Gd based electrolytes in the IL are not very different; therefore, a change in conductivity could not explain the behavior (cf. Figure 8). Also the change in the reference electrode potential and thus the true reference scale between the experiments shown in Figure $5 \mathrm{~b}$ is not considered as the cause as further lowering the potential only resulted in IL decomposition. It is known that the interfacial structure in ILs can show complicated multilayer structures (55), but it still needs further research to see if this has an impact under the current experimental conditions.

\section{Conclusions}

BMIm DCA does permit the deposition of $\mathrm{Gd}$ metal with relative ease. The deposition of $\mathrm{Pt}$, however, is much more difficult. This is assigned to the formation of strong complexes especially of $\mathrm{Pt}(\mathrm{II})$ shifting the potential needed for reduction so negative that the IL decomposition takes place in parallel, or possibly to the presence of interfacial layers blocking the deposition. Therefore, the current approach needs to be modified in order to permit indeed deposition of $\mathrm{Gd}$ and $\mathrm{Pt}$ from the same IL. One promising pathway might be the replacement of the IL cation by a more stable one while keeping DCA as the anion.

\section{Acknowledgments}

The project leading to this publication has received funding from the Fuel Cells and Hydrogen 2 Joint Undertaking under grant agreement No 700127, INSPIRE. This Joint Undertaking receives support from the European Union's Horizon 2020 research and innovation programme, Hydrogen Europe Industry and Hydrogen Europe Research. We thank Prof. Holger Fritze (Clausthal University of Technology) for providing a software to fit the NA data automatically.

\section{References}

1. O. Gröger, H. A. Gasteiger, and J.-P. Suchsland, J. Electrochem. Soc., 162, A2605 (2015).

2. A. U. Nilekar, and M. Mavrikakis, Surf. Sci., 602, L89 (2008).

3. J. K. Norskov, J. Rossmeisl, A. Logadottir, L. Lindqvist, J. R. Kitchin, T. Bligaard, and H. Jonsson, J. Phys. Chem. B, 108, 17886 (2004).

4. U. A. Paulus, T. J. Schmidt, H. A. Gasteiger, and R. J. Behm, J. Electroanal. Chem., 495, 134 (2001).

5. H. A. Gasteiger, S. S. Kocha, B. Sompalli, and F. T. Wagner, Appl. Catal., B, 56, 9 (2005).

6. D. Papageorgopoulos, Fuel Cells Program, in, U. D. o. Energy Editor, https://www.hydrogen.energy.gov/pdfs/review15/fc000 papageorgopoulos 2015 o.pdf (2015).

7. I. E. L. Stephens, A. S. Bondarenko, U. Gronbjerg, J. Rossmeisl, and I. Chorkendorff, Energy Environ. Sci., 5, 6744 (2012).

8. V. Stamenkovic, B. S. Mun, K. J. J. Mayrhofer, P. N. Ross, N. M. Markovic, J. Rossmeisl, J. Greeley, and J. K. Nørskov, Angew. Chem., Int. Ed., 45, 2897 (2006). 
9. C. Wang, N. M. Markovic, and V. R. Stamenkovic, ACS Catal., 2, 891 (2012).

10. V. Beermann, M. Gocyla, E. Willinger, S. Rudi, M. Heggen, R. E. DuninBorkowski, M.-G. Willinger, and P. Strasser, Nano Lett., 16, 1719 (2016).

11. L. Gan, C. Cui, S. Rudi, and P. Strasser, Top. Catal., 57, 236 (2014).

12. M. Oezaslan, F. Hasché, and P. Strasser, J. Phys. Chem. Lett., 4, 3273 (2013).

13. M. Escudero-Escribano, P. Malacrida, M. H. Hansen, U. G. Vej-Hansen, A. Velázquez-Palenzuela, V. Tripkovic, J. Schiøtz, J. Rossmeisl, I. E. L. Stephens, and I. Chorkendorff, Science, 352, 73 (2016).

14. J. F. Drillet, A. Ee, J. Friedemann, R. Kötz, B. Schnyder, and V. M. Schmidt, Electrochim. Acta, 47, 1983 (2002).

15. H. Wu, D. Wexler, and G. Wang, J. Alloys Compd., 488, 195 (2009).

16. V. Stamenković, T. J. Schmidt, P. N. Ross, and N. M. Marković, J. Electroanal. Chem., 554-555, 191 (2003).

17. N. Becknell, Y. Kang, C. Chen, J. Resasco, N. Kornienko, J. Guo, N. M. Markovic, G. A. Somorjai, V. R. Stamenkovic, and P. Yang, J. Am. Chem. Soc., 137, 15817 (2015).

18. J. R. Greer, Science, 343, 1319 (2014).

19. C. Chen, Y. Kang, Z. Huo, Z. Zhu, W. Huang, H. L. Xin, J. D. Snyder, D. Li, J. A. Herron, M. Mavrikakis, M. Chi, K. L. More, Y. Li, N. M. Markovic, G. A. Somorjai, P. Yang, and V. R. Stamenkovic, Science, 343, 1339 (2014).

20. J. Greeley, I. E. L. Stephens, A. S. Bondarenko, T. P. Johansson, H. A. Hansen, T. F. Jaramillo, J. Rossmeisl, I. Chorkendorff, and J. K. Nørskov, Nat. Chem., 1, 552 (2009). 21. A. F. Pedersen, E. T. Ulrikkeholm, M. Escudero-Escribano, T. P. Johansson, P. Malacrida, C. M. Pedersen, M. H. Hansen, K. D. Jensen, J. Rossmeisl, D. Friebel, A. Nilsson, I. Chorkendorff, and I. E. L. Stephens, Nano Energy, 29, 249 (2016).

22. A. Velázquez-Palenzuela, F. Masini, A. F. Pedersen, M. Escudero-Escribano, D. Deiana, P. Malacrida, T. W. Hansen, D. Friebel, A. Nilsson, I. E. L. Stephens, and I. Chorkendorff, J. Catal., 328, 297 (2015).

23. M. Escudero-Escribano, A. Verdaguer-Casadevall, P. Malacrida, U. Grønbjerg, B. P. Knudsen, A. K. Jepsen, J. Rossmeisl, I. E. L. Stephens, and I. Chorkendorff, J. Am. Chem. Soc., 134, 16476 (2012).

24. J. R. Kitchin, J. K. Nørskov, M. A. Barteau, and J. G. Chen, Phys. Rev. Lett., 93, 156801 (2004).

25. M. Mavrikakis, B. Hammer, and J. K. Nørskov, Phys. Rev. Lett., 81, 2819 (1998).

26. S. J. Yoo, K.-S. Lee, S. J. Hwang, Y.-H. Cho, S.-K. Kim, J. W. Yun, Y.-E. Sung, and T.-H. Lim, Int. J. Hydrogen Energy, 37, 9758 (2012).

27. S. J. Yoo, and Y.-E. Sung, Surf. Sci., 631, 272 (2015).

28. N. Lindahl, E. Zamburlini, L. Feng, H. Grönbeck, M. Escudero-Escribano, I. E. L.

Stephens, I. Chorkendorff, C. Langhammer, and B. Wickman, Adv. Mater. Interfaces, 4, 1700311 (2017).

29. H. Kondo, M. Matsumiya, K. Tsunashima, and S. Kodama, Electrochim. Acta, 66, 313 (2012).

30. M. Matsumiya, M. Ishii, R. Kazama, and S. Kawakami, Electrochim. Acta, 146, 371 (2014).

31. J. Lodermeyer, M. Multerer, M. Zistler, S. Jordan, H. J. Gores, W. Kipferl, E. Diaconu, M. Sperl, and G. Bayreuther, J. Electrochem. Soc., 153, C242 (2006).

32. L. M. Glukhov, A. A. Greish, and L. M. Kustov, Russ. J. Phys. Chem. A, 84, 104 (2010). 
33. A. I. Bhatt, I. May, V. A. Volkovich, D. Collison, M. Helliwell, I. B. Polovov, and R. G. Lewin, Inorg. Chem., 44, 4934 (2005).

34. S. Legeai, S. Diliberto, N. Stein, C. Boulanger, J. Estager, N. Papaiconomou, and M. Draye, Electrochem. Commun., 10, 1661 (2008).

35. Q. B. Zhang, C. Yang, Y. X. Hua, Y. Li, and P. Dong, Phys. Chem. Chem. Phys., 17, 4701 (2015).

36. L.-H. Chou, W. E. Cleland, and C. L. Hussey, Inorg. Chem., 51, 11450 (2012).

37. L.-H. Chou, and C. L. Hussey, Inorg. Chem., 53, 5750 (2014).

38. M. Yamagata, Y. Katayama, and T. Miura, J. Electrochem. Soc., 153, E5 (2006).

39. Y. Pan, and C. L. Hussey, Inorg. Chem., 52, 3241 (2013).

40. A. Ispas, M. Buschbeck, S. Pitula, A. Mudring, M. Uhlemann, A. Bund, and F. Endres, ECS Trans., 16 (45), 119 (2009).

41. A. I. Bhatt, I. May, V. A. Volkovich, M. E. Hetherington, B. Lewin, R. C. Thied, and N. Ertok, J. Chem. Soc., Dalton Trans., 4532 (2002).

42. H. Ota, M. Matsumiya, N. Sasaya, K. Nishihata, and K. Tsunashima, Electrochim. Acta, 222, 20 (2016).

43. A. Kurachi, M. Matsumiya, K. Tsunashima, and S. Kodama, J. Appl. Electrochem., 42, 961 (2012).

44. L. Asen, W. Ju, E. Mostafa, S. Martens, U. Heiz, U. Stimming, and O. Schneider, ECS Trans., 75 (15), 323 (2016).

45. P. He, H. Liu, Z. Li, and J. Li, J. Electrochem. Soc., 152, E146 (2005).

46. D. Zhang, W. C. Chang, T. Okajima, and T. Ohsaka, Langmuir, 27, 14662 (2011).

47. Y. C. Celik, G. Pulletikurthi, and F. Endres, J. Solid State Electrochem., 20, 2781 (2016).

48. H.-Y. Huang, C.-J. Su, C.-L. Kao, and P.-Y. Chen, J. Electroanal. Chem., 650, 1 (2010).

49. A. Glidle, A. R. Hillman, and S. Bruckenstein, J. Electroanal. Chem., 318, 411 (1991).

50. G. Sauerbrey, Z. Phys., 155, 206 (1959).

51. A. J. Bard, and L. R. Faulkner, Electrochemical Methods: Fundamentals and Applications, John Wiley \& Sons, New York (2001).

52. T. Carstens, A. Ispas, N. Borisenko, R. Atkin, A. Bund, and F. Endres, Electrochim. Acta, 197, 374 (2016).

53. R. Atkin, N. Borisenko, M. Druschler, F. Endres, R. Hayes, B. Huber, and B. Roling, J. Mol. Liq., 192, 44 (2014).

54. S. Zein El Abedin, J. Solid State Electrochem., 16, 775 (2012).

55. N. Borisenko, A. Lahiri, G. Pulletikurthi, T. Cui, T. Carstens, J. Zahlbach, R. Atkin, and F. Endres, Faraday Discuss., 206, 459 (2018). 